\title{
Journal of

\section{Electrodeposited Pt on three-dimensional interconnected graphene as a free-standing electrode for fuel cell application $\dagger$}

\author{
Thandavarayan Maiyalagan, $\$$ Xiaochen Dong, $\$$ Peng Chen* and Xin Wang*
}

Received 12th December 2011, Accepted 30th January 2012

DOI: $10.1039 / \mathrm{c} 2 \mathrm{jm} 16541 \mathrm{~d}$

\begin{abstract}
A three-dimensional interconnected graphene monolith was used as an electrode support for pulsed electrochemical deposition of platinum (Pt) nanoparticles. Pt nanoparticles with well-defined morphology and small size can be obtained by controlling electrodeposition potential and time. Electrochemical characterization was carried out to examine the electrocatalytic activity of this monolithic electrode towards methanol oxidation in acidic media. The results show that the carbon material surface and structure have a strong influence on the Pt particle size and morphology. Compared with the three-dimensional scaffold of carbon fibers, the three-dimensional graphene when used as a free-standing electrode support resulted in much improved catalytic activity for methanol oxidation in fuel cells due to its three-dimensionally interconnected seamless porous structure, high surface area and high conductivity.
\end{abstract}

\section{Introduction}

Graphene, a two-dimensional (2D) nanomaterial with a single sheet of carbon atoms packed in a hexagonal lattice, has recently attracted attention due to its fascinating properties, such as high surface area, extraordinary conductivity due to high charge carrier mobility and capacity and excellent mechanical strength. ${ }^{1-4}$ These unique properties make graphene a promising material for energy conversion and storage applications..$^{5-9}$ It is believed that developing macroscopic three-dimensional (3D) architecture of graphene will further extend its abilities towards these applications. There are many reports in the literature on graphene powder as a catalyst support for fuel cells. ${ }^{10,11}$ The methods of preparation of the Pt nanoparticles and alloys on the graphene support have attracted much interest in view of superior electrocatalytic activity for fuel cell applications. ${ }^{12,13}$ However, similar to conventional fuel cell electrodes, these materials still suffer from insufficient Pt utilization due to the segregation by an insulating PTFE binder in the real fuel cell electrode.

School of Chemical and Biomedical Engineering, Nanyang Technological University,62 Nanyang Drive, 639798, Singapore.E-mail: WangXin@ ntu.edu.sg; ChenPeng@ntu.edu.sg; Fax: +(65) 6794 7553; Tel: +(65) 63168790

$\dagger$ Electronic supplementary information (ESI) available. See DOI: 10.1039/c2jm16541d

\$ Both authors contributed equally to this work.
Recently, a novel 3D interconnected graphene network has been reported, ${ }^{14}$ which opens up a new promising way for the application of graphene based materials. Exhibiting an open-pore honeycomb structure, this 3D graphene has an exceptionally large void volume, high surface area, high corrosion resistance and high electrical conductivity. All these properties make it ideal as the electrode support material for fuel cell applications. Firstly, high corrosion resistance of the graphene material can significantly reduce the support corrosion problem, which has been identified as one of the main reasons for the quick performance loss of fuel cells. ${ }^{15}$ Secondly, high electrical conductivity is essential for efficient electron conduction through the electrode. Compared to the powder form, the unique monolithic nature can better maintain its conductivity by eliminating junction resistance when used as an electrode. Thirdly, the high surface area of the 3D graphene allows uniform and high loading of catalysts (here, Pt nanoparticles). Lastly, the interconnected pores may potentially offer low resistance to fluid flow and ensure efficient mass transfer during fuel cell operation.

In this work, the free-standing 3D graphene was examined for the first time as an electrode support for methanol oxidation and compared with the free-standing carbon fiber $(\mathrm{CF})$ material ${ }^{16}$ with a similar three-dimensional structure. The present investigation provides insights and demonstrates potentials of this material for fuel cell applications. The 3D graphene electrode poses two major challenges. The first one relates to synthesizing and uniformly depositing nano-sized Pt electro-catalyst throughout the three-dimensional matrix. The second challenge is the formation of the proton conductor network across the three-dimensional electrode connecting the electrocatalytic sites and the proton exchange membrane. To address the first issue, pulse electrodeposition is adopted which ensures that all the deposited Pt nanoparticles (NPs) are electrically accessible. Furthermore, pulse electrodeposition exhibits several advantages over direct current electrodeposition in the control of particle size, uniform distribution and strong adhesion of the NPs on the substrate. ${ }^{17-19}$ The second issue of protonic conductivity in the fuel cell electrode could be addressed by employing a hydrophilic Nafion electrolyte.

Towards that end, deposition of Pt-NPs on the 3D monolithic graphene architecture is designed and improved activity for methanol oxidation is reported. The improved activity and stability of the electrode were attributed to the unique 3D monolithic architecture with outstanding conductivity and in the absence of junction resistance, which leads to efficient electron conduction and mass transport. 


\section{Experimental}

\subsection{Synthesis of 3D graphene foams}

The 3D graphene foams with continuous single and few-layer graphenes were synthesized by chemical vapour deposition using nickel foam as the template and ethanol as precursors. ${ }^{14,20}$ Typically, nickel foams $\left(0.5 \mathrm{~mm}\right.$ in thickness, $320 \mathrm{~g} \mathrm{~m}^{-2}$ in areal density) were cut into $2 \times 2 \mathrm{~cm}$ and placed in a quartz tube furnace with temperature gradually increased to $1000{ }^{\circ} \mathrm{C}$ under $\mathrm{H}_{2}(25 \mathrm{sccm})$ and $\mathrm{Ar}$ $(50 \mathrm{sccm})$ environment. After annealing for $10 \mathrm{~min}$ to clean the nickel surface, the ethanol vapour was introduced into the tube by $\mathrm{H}_{2} / \mathrm{Ar}$ mixture gas at ambient pressure. $20 \mathrm{~min}$ later, the samples were rapidly cooled to room temperature at a rate of $\sim 100^{\circ} \mathrm{C} \mathrm{min}^{-1}$. After the growth process, the nickel substrates were etched away with $\mathrm{HCl}$ (3 M) solution at $80^{\circ} \mathrm{C}$ to obtain free-standing 3D graphene foams.

\subsection{Electrochemical deposition}

A pulse potential profile of $0 \mathrm{mV}(500 \mathrm{~ms})-1000 \mathrm{mV}(200 \mathrm{~ms})-0 \mathrm{mV}$ $(500 \mathrm{~ms})(v s . \mathrm{Ag} / \mathrm{AgCl} / 3 \mathrm{M} \mathrm{KCl})$ with different numbers of pulses was applied for the Pt deposition. After electrodeposition of Pt particles from the $\mathrm{H}_{2} \mathrm{PtCl}_{6}$ solution, the catalyst modified three-dimensional graphene support (Pt/3D-graphene) was washed with de-ionized water and then dried.

\subsection{Characterization}

The thickness and microstructure of the 3D graphene foams were examined by a WITec CRM200 Confocal Raman spectrophotometer (laser wavelength $488 \mathrm{~nm}$ ). The morphology of the samples was observed by a field-emission scanning electron microscope (JEOL-JSM6700-FESEM). X-Ray diffraction (XRD) patterns were collected with a Bruker D8 Advanced Diffractometer using $\mathrm{Cu} \mathrm{K}_{\alpha}$ radiation.

\subsection{Electrochemical measurements}

The electrochemical properties of the free-standing 3D graphene electrodes were examined using an Autolab Electrochemical Working Station in a three-electrode system in $0.5 \mathrm{M} \mathrm{H}_{2} \mathrm{SO}_{4}$ electrolyte at room temperature. Pt gauze was used as the counter electrode, $\mathrm{Ag} / \mathrm{AgCl}$ as the reference electrode and $3 \mathrm{D}$ graphene as the work electrode directly. Stable data were recorded after 20 cycles. The potential range for cyclic voltammetry (CV) measurements was -0.2 to $+1.0 \mathrm{~V}$ at a scan rate of $50 \mathrm{mV} \mathrm{s}^{-1}$.

\section{Results and discussion}

\subsection{Substrate characterization}

Fig. 1a provides a photograph of the obtained free standing graphene foam which is flexible and black. The monolithic and porous 3D graphene architecture can be clearly observed in Fig. 1a and 2a. The 3D graphene was characterized by Raman spectroscopy, where two characteristic peaks at $\sim 1560 \mathrm{~cm}^{-1}$ (G-band) and $\sim 2700 \mathrm{~cm}^{-1}$ (2D-band) $)^{21}$ are evident.

As revealed by the integrated intensity ratio of $\mathrm{G}$ and $2 \mathrm{D}$ bands $\left(I_{\mathrm{G}} / I_{2 \mathrm{D}}\right)$ in the Raman spectrum, the $3 \mathrm{D}$ graphene exhibits singlelayer and few-layer domains (Fig. 1b). ${ }^{22}$ Because $I_{\mathrm{G}}$ increases monotonically with the increasing graphene thickness whereas $I_{2 \mathrm{D}}$ is
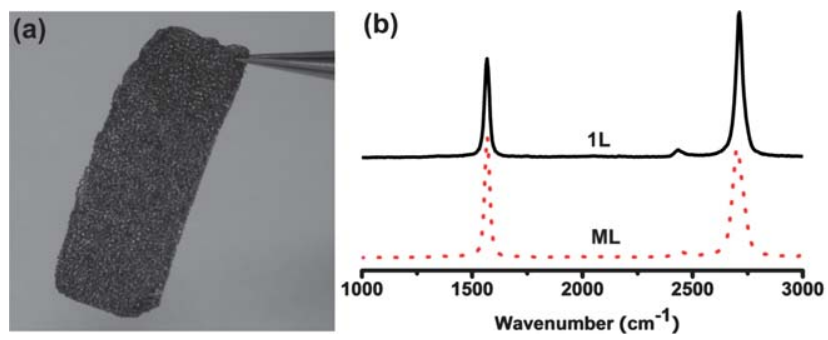

Fig. 1 (a) Photograph of 3D graphene foam and (b) typical Raman spectra measured at different spots of $3 \mathrm{D}$ graphene foam reveal the existence of single layer (1L) and few-layer (ML) domains.

relatively stable, $I_{\mathrm{G}} / I_{2 \mathrm{D}}$ scales linearly with the number of graphene layers (up to 4 layers). ${ }^{23}$

The Raman D-band (at $\sim 1350 \mathrm{~cm}^{-1}$ ) is originated from the disordered carbon in graphene, and its intensity indicates the density of defects in the as-grown graphene film. ${ }^{24}$ The extremely weak D-band in the Raman spectra of the free-standing 3D graphene (Fig. 1b) demonstrates the high quality of the obtained graphene.

Fig. $2 \mathrm{a}$ and $\mathrm{b}$ show the morphology of $3 \mathrm{D}$ graphene and carbon fiber support (carbon paper). The inset in Fig. 2a shows the surface morphology of $3 \mathrm{D}$ graphene at a higher magnification. SEM analyses reveal that the carbon paper consists of overlapped crossed fibers (Fig. 2b) and the diameter of the fibers is about $5 \mu \mathrm{m}$. Controlling the size and dispersion of Pt NPs on 3D graphene is critical for their application in fuel cells. In our study, the Pt NPs with controllable size and dispersion are achieved by controlling the pulse deposition in aqueous solution. SEM analyses revealed that pulse deposition (200 pulses) led to well defined spherical-type Pt particles uniformly dispersed on the 3D graphene surface, ranging from 10 to $30 \mathrm{~nm}$ in size (Fig. 2c). Control experiments by the conventional electrodeposition technique in $1 \mathrm{mM} \mathrm{H}_{2} \mathrm{PtCl}_{6}+1 \mathrm{M} \mathrm{K}_{2} \mathrm{SO}_{4}$ at $-200 \mathrm{mV}$ vs. SCE for
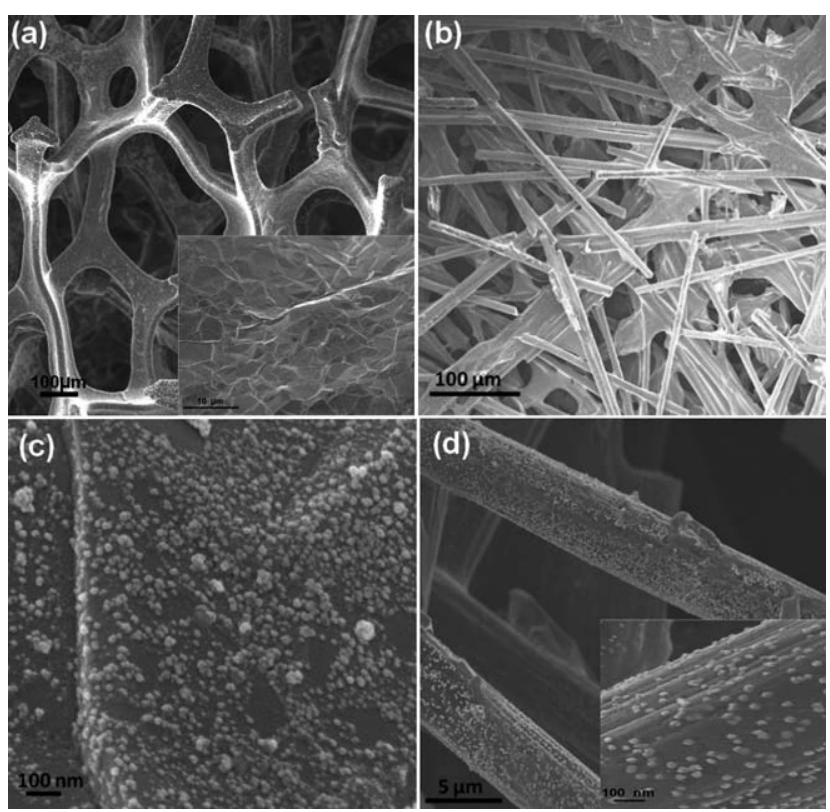

Fig. 2 SEM images of the (a) 3D graphene support (b) carbon fiber support (c) Pt/3 D-GN catalyst and (d) Pt/CF catalyst. Insets in (a) and (d) are the enlarged pictures. 
300 seconds were also conducted. Thus conventional electrodeposition leads to higher particle sizes of about 100-200 nm (ESI, Fig. S1 $\dagger$ ). TEM images (ESI†, Fig. S2b) also confirm the Pt particles on 3D graphene. The uniform and dense distribution of smaller platinum particles on the 3D graphene electrode substrate desirably provides abundant catalytic sites. As a result, high electro-catalytic activity was obtained from the modified 3D graphene electrode. Similar conditions of electrodeposition were employed also for the carbon fiber electrode. Fig. 2d shows a low-magnification SEM image of porous carbon paper decorated with Pt NPs. A higher magnification SEM image (Fig. 2d, inset) indicates that a large number of NPs, with particle sizes larger than $30 \mathrm{~nm}$, cover the whole surface of the carbon fiber. It is also observed that the dispersion of Pt NPs is more uniform and denser in $\mathrm{Pt} / 3 \mathrm{D}$-graphene than in $\mathrm{Pt} / \mathrm{CF}$ presumably due to the surface flatness of 3D-graphene compared to a highly curved surface of carbon fiber. Therefore, 3D-graphene is proved to be a better catalyst support than carbon fiber.

XRD analysis shown in Fig. 3 reveals that the prepared catalysts exhibit a typical face-centered cubic (fcc) Pt lattice structure. The Pt/ $3 \mathrm{D}$-graphene catalyst shows a diffraction peak at $\sim 26^{\circ}$, confirming that the graphitic nature of 3D-graphene is still maintained after the catalyst preparation. In contrast, the XRD pattern of the $\mathrm{Pt} / \mathrm{CF}$ paper exhibits one broad peak centered at $\sim 25.6^{\circ}$, indicating the amorphous nature. The average particle sizes of $\mathrm{Pt} / 3 \mathrm{D}$-graphene and $\mathrm{Pt} / \mathrm{CF}$, calculated from the $\left(\begin{array}{lll}1 & 1 & 1\end{array}\right)$ peak using the Debye-Scherrer equation, are 7.89 and $13.6 \mathrm{~nm}$, respectively. The particle sizes observed by SEM are larger than those estimated from XRD, implying that the agglomerates comprise much smaller particles, particularly in the case of carbon fiber.

\subsection{Intrinsic activity of Pt NPs for methanol electro-oxidation}

Fig. 4a shows the cyclic voltammogram of both catalytic substrates in nitrogen purged $0.5 \mathrm{M} \mathrm{H}_{2} \mathrm{SO}_{4}$. Pt/3D-graphene exhibits larger double-layer capacitance than $\mathrm{Pt} / \mathrm{CF}$, reflecting that the electrochemically active surface area of 3D-graphene is significantly larger than that of carbon fiber (Fig. 4a). In addition, the electrochemically active $\mathrm{Pt}$ area, determined by integrating the hydrogen adsorption area, is found to be $58 \%$ higher for $\mathrm{Pt} / 3 \mathrm{D}$-graphene than for $\mathrm{Pt} / \mathrm{CF}$. The larger $\mathrm{Pt}$ area in $\mathrm{Pt} / 3 \mathrm{D}$-graphene is ascribed to better dispersion of $\mathrm{Pt}$ on 3D-graphene, which is confirmed by the SEM analysis.

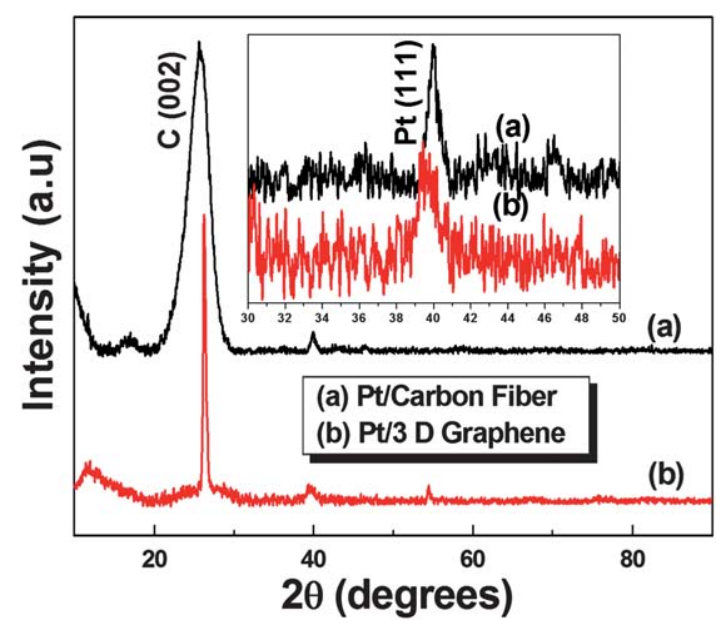

Fig. 3 XRD patterns of Pt/3 D-GN and Pt/CF catalysts.
To evaluate the electro-catalytic activity of $\mathrm{Pt} / 3 \mathrm{D}$-graphene towards methanol electro-oxidation, cyclic voltammograms were recorded in a nitrogen purged solution of $0.5 \mathrm{M} \mathrm{H}_{2} \mathrm{SO}_{4}$ containing $1 \mathrm{M} \mathrm{CH}_{3} \mathrm{OH}$ at a scan rate of $50 \mathrm{mV} \mathrm{s}^{-1}$ and the current reported was normalized by the $\mathrm{Pt}$ active surface area. On the forward potential sweep (Fig. 4b), the current increased slowly at lower potentials, and then quickly increased at potentials higher than 0.5 V. These features of the voltammogram, which are similar to those of the Pt metal, suggest that the well dispersed Pt NPs on the 3D graphene are electrochemically active. ${ }^{25}$ The magnitude of the peak current density is directly proportional to the amount of methanol oxidized at the electrode. The peak current density of the forward anodic peaks $\left(I_{\mathrm{f}}\right)$ observed with $3 \mathrm{D}$-graphene is approximately $1.6 \mathrm{~mA} \mathrm{~cm}{ }^{-2}$, nearly two times the peak current density of the carbon fiber $\left(0.8 \mathrm{~mA} \mathrm{~cm}^{-2}\right)$; this result suggests that 3D-graphene plays a critical role in promoting methanol oxidation of Pt NPs. The current density of commercial $\mathrm{Pt} / \mathrm{C}^{26}$ catalysts is $1.39 \mathrm{~mA} \mathrm{~cm}-2$ which is lower than the $3 \mathrm{D}$ graphene catalysts. The ratio of the forward anodic peak current density $\left(I_{\mathrm{f}}\right)$ to the reverse anodic peak current density $\left(I_{\mathrm{b}}\right)$ can be used to describe the tolerance of $\mathrm{Pt}$ catalysts to $\mathrm{CO}$ and other carbonaceous species. The $I_{\mathrm{f}} / I_{\mathrm{b}}$ ratio for commercial $\mathrm{Pt} / \mathrm{C}$ is about 0.80 . The reported value of the $I_{\mathrm{f}} / I_{\mathrm{b}}$ ratio of commercial E-TEK catalyst is $\sim 1$ (ref. 27-30) and three-dimensional Pt-on-Pd bimetallic nanodendrites supported on graphene nanosheets is 1.25 (ref. 31). In the present study, the carbon fibersupported Pt NPs have a similar $I_{\mathrm{f}} / I_{\mathrm{b}}$ ratio as the E-TEK catalyst. The 3D graphene-supported Pt NPs have a ratio of 2.25, suggesting that graphene-supported Pt NPs generate a more complete oxidation of methanol to carbon dioxide. Taken together, the highly conductive Pt/3D-graphene electrode with smaller Pt NPs sizes and better dispersion of NPs exhibits superior intrinsic activity for methanol electro-oxidation.

Chronoamperometric measurements of $\mathrm{Pt} / 3 \mathrm{D}$-graphene and $\mathrm{Pt} / \mathrm{CF}$ are shown in Fig. 5, which reflect the activity and stability of the catalyst to catalyse methanol. Under a given potential of $0.6 \mathrm{~V}$, $\mathrm{Pt} / 3 \mathrm{D}$-graphene shows a higher initial current and a slower decay of the peak current with time, suggesting a better catalytic activity and stability than $\mathrm{Pt} / \mathrm{CF}$.

High catalytic efficiency for 3D graphene-supported Pt was achieved due to the maximization of the three-phase boundary (TPB) in the electrode by depositing Pt NPs on the outermost surface area of an established porous network. In our method, a free-standing 3D graphene was constructed; Pt NPs were then electro-deposited on the $3 \mathrm{D}$ graphene in a liquid solution. Only those sites that are electrolyte accessible and electron accessible can have the deposition of Pt NPs. The advantages of a catalytic electrode made with this 3D graphene include: (1) its unique monolithic network structure offers continuous and multiplexing pathways for electron conduction; (2) Pt NPs are electrodeposited on the most efficient contact zones with guaranteed electronic and electrolytic pathways in the 3D graphene; (3) the open vacancies (pores) mostly in the meso- to macro-size range can be effectively covered by Nafion electrolytes, which facilitates the maximization of the three-phase boundary where the electrochemical reaction takes place; (4) the high porosity of $3 \mathrm{D}$ graphene also benefits the mass transfer process within the catalyst layer resulting in further improvement for Pt utilization; and (5) the Pt/3D-graphene electrode also showed higher stability and higher conductivity. Combining these advantages, a much improved performance for methanol oxidation is achieved. 

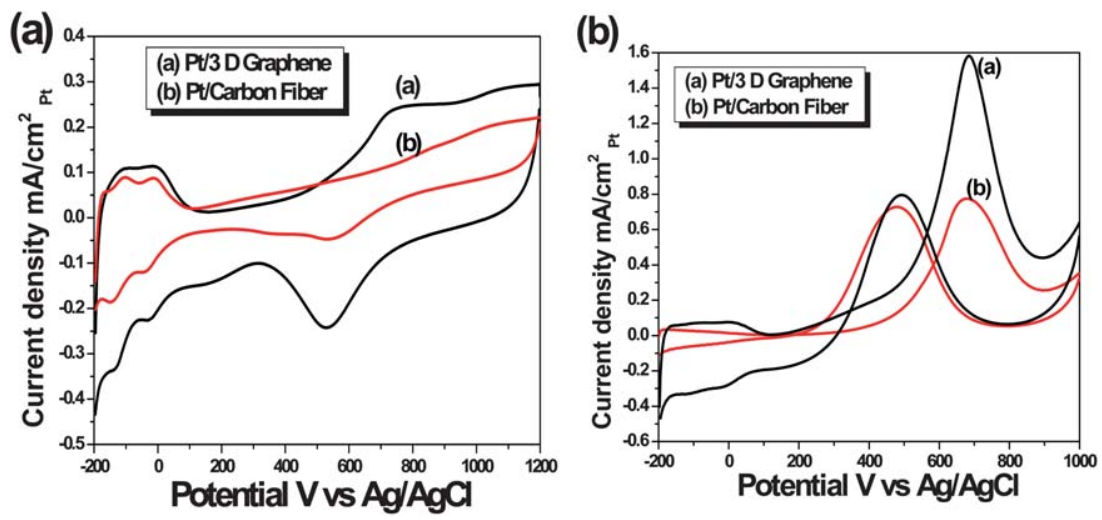

Fig. 4 (a) Cyclic voltammograms of $\mathrm{Pt} / 3 \mathrm{D}$-graphene and $\mathrm{Pt} / \mathrm{CF}$ catalysts in $\mathrm{H}_{2} \mathrm{SO}_{4}$ (scan rate: $50 \mathrm{mV} \mathrm{s}^{-1}$ ) and (b) in a mixture solution of $0.5 \mathrm{M} \mathrm{H} \mathrm{H}_{2} \mathrm{SO}_{4}$ and $1 \mathrm{M} \mathrm{CH}_{3} \mathrm{OH}$ (scan rate: $50 \mathrm{mV} \mathrm{s}^{-1}$ ).

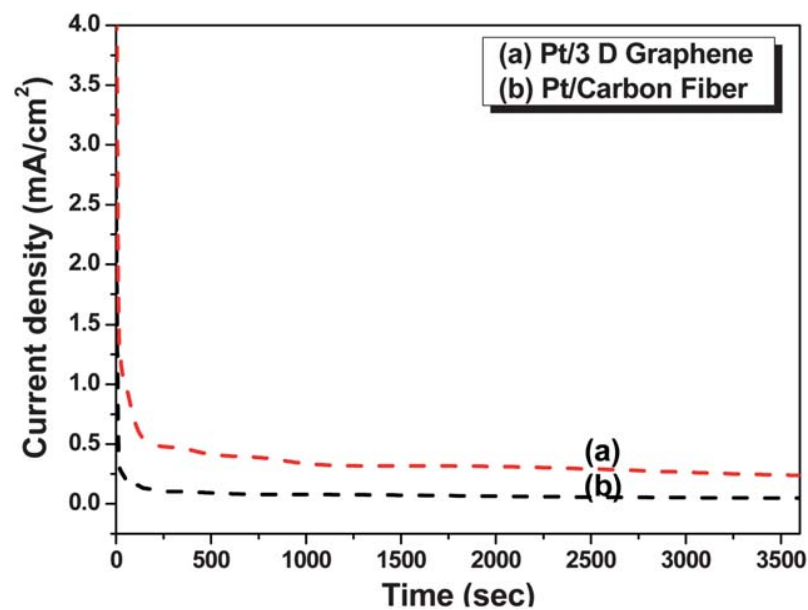

Fig. 5 Chronoamperometric curves at $0.6 \mathrm{~V}$ for $3600 \mathrm{~s}$ of (a) $\mathrm{Pt} / 3 \mathrm{D}-$ graphene and (b) $\mathrm{Pt} / \mathrm{CF}$ electro-catalysts in $0.5 \mathrm{M} \mathrm{H}_{2} \mathrm{SO}_{4} / 1 \mathrm{M} \mathrm{CH}_{3} \mathrm{OH}$ solutions at $25^{\circ} \mathrm{C}$.

One additional benefit of this $3 \mathrm{D}$ graphene is its much lighter weight compared to the similar sized carbon fiber. This could be advantageous for applications where the system weight is a critical parameter.

\section{Conclusions}

Platinum nanoparticles deposited on 3D graphene and carbon fiber scaffold by the pulse electrodeposition method exhibit different catalytic activity towards methanol oxidation. This difference in catalytic activity can be attributed to the geometry difference of these carbonaceous supports. The enhancement in the $\mathrm{Pt} / 3 \mathrm{D}$-graphene catalyst is attributed to the superior electrical conductivity, large surface area and efficient mass transport, and dense coating of small platinum nanoparticles. Detailed electrochemical characterization shows the 3D graphene structure as a new kind of supporting material with higher catalytic activity and stability for methanol oxidation. The present approach can be readily extended by decorating free-standing 3D graphene with nanoparticles of other noble metals and their alloys for various electro-catalysis applications or electrochemical sensors.

\section{Acknowledgements}

The authors are deeply grateful to the National Research Foundation (Singapore) for the Competitive Research Program (2009 NRFCRP001-032) and the Ministry of Education (Singapore) for the academic research fund ARC 2/10 (MOE2009-T2-2-024).

\section{Notes and references}

1 M. D. Stoller, S. Park, Y. Zhu, J. An and R. S. Ruoff, Nano Lett., 2008, 8(10), 3498-3502.

2 Y. X. Xu and G. Q. Shi, J. Mater. Chem., 2011, 21, 3311-3323.

3 C. Mattevi, H. Kim and M. Chhowalla, J. Mater. Chem., 2011, 21, 3324.

4 C. Lee, X. Wei, J. W. Kysar and J. Hone, Science, 2008, 321(5887), 385-388.

5 Y. Shao, S. Zhang, M. H. Engelhard, G. Li, G. Shao, Y. Wang, J. Liu, I. A. Aksay and Y. Lin, J. Mater. Chem., 2010, 20, 7491-7496.

6 Y. Zhang, T. Mori, L. Niu and J. Ye, Energy Environ. Sci., 2011, 4, $4517-4521$.

7 S. Y. Wang, S. P. Jiang and X. Wang, Phys. Chem. Chem. Phys., 2011, 13, 6883-6891.

8 J.-J. Shi, G.-H. Yang and J.-J. Zhu, J. Mater. Chem., 2011, 21, $7343-$ 7349.

9 Y. Sun, Q. Wu and G. Shi, Energy Environ. Sci., 2011, 4, 1113-1132.

10 J. Hou, Y. Shao, M. W. Ellis, R. B. Moore and B. Yi, Phys. Chem. Chem. Phys., 2011, 13, 4083-4094.

11 Y. Hu, H. Zhang, P. Wu, H. Zhang, B. Zhou and C. Cai, Phys. Chem. Chem. Phys., 2011, 13, 15384-15402.

12 Y. G. Zhou, J. J. Chen, F. B. Wang, Z. H. Sheng and X. H. Xia, Chem. Commun., 2010, 46, 5951-5953.

13 J.-D. Qiu, G.-C. Wang, R.-P. Liang, X.-H. Xia and H.-W. Yu, J. Phys. Chem. C, 2011, 115, 15639-15645.

14 Z. Chen, W. Ren, L. Gao, B. Liu, S. Pei and H.-M. Cheng, Nat. Mater., 2011, 10, 424-428.

15 X. Wang, W. Z. Li and Y. S. Yan, J. Power Sources, 2006, 158, 154 159.

16 S. Uhm, H. L. Lee, Y. Kwon and J. Lee, Angew. Chem., Int. Ed., 2008, 47, 10163-10166.

17 H. Kim and B. N. Popov, Electrochem. Solid-State Lett., 2004, 7, A71-A74.

18 H. Kim, N. P. Subramanian and B. N. Popov, J. Power Sources, 2004, 138, 14-24.

19 C. Coutanceau, A. F. Rakotondrainibé, A. Lima, E. Garnier, S. Pronier, J.-M. Léger and C. Lamy, J. Appl. Electrochem., 2004, 34, 61-66. 
20 X. Dong, W. Fang, C. Y. Su, Y. H. Chen, L. J. Li, W. Huang and P. Chen, Carbon, 2011, 49, 3672-3678.

21 A. C. Ferrari, J. C. Meyer, V. Scardaci, C. Casiraghi, M. Lazzeri, F. Mauri, S. Piscanec, D. Jiang, K. S. Novoselov, S. Roth and A. K. Geim, Phys. Rev. Lett., 2006, 97, 187401-187404.

22 Y. Huang, X. Dong, Y. Shi, C. M. Li, L. J. Li and P. Chen, Nanoscale, 2010, 2, 1485-1488.

23 D. Graf, F. Molitor, K. Ensslin, C. Stampfer, A. Jungen, C. Hierold and L. Wirtz, Nano Lett., 2006, 7, 238-242.

24 M. S. Dresselhaus, A. Jorio, M. Hofmann, G. Dresselhaus and R. Saito, Nano Lett., 2010, 10, 751-758.
25 D. Pletcher and S. Sotiropoulos, J. Chem. Soc., Faraday Trans., 1994, 90, 3663-3668.

26 F. Su, J. Zeng, X. Bao, Y. Yu, J. Y. Lee and X. S. Zhao, Chem. Mater., 2005, 17, 3960-3967.

27 V. Raghuveer and A. Manthiram, J. Electrochem. Soc., 2005, 152, A1504-A1510.

28 T. C. Deivaraj and J. Y. Lee, J. Power Sources, 2005, 142, $43-49$.

29 Z. C. Wang, D. D. Zhao, G.-Y. Zhao and H. L. Li, J. Solid State Electrochem., 2009, 13, 371-376.

30 S. Guo, S. Dong and E. Wang, Small, 2009, 5, 1869-1876.

31 S. Guo, S. Dong and E. Wang, ACS Nano, 2010, 4, 547-555. 